\title{
Sustainable arsenic mitigation and management through community participation
}

\author{
A.K. Ghosh, A. Kumar, R. Kumar \& M. Ali \\ Mahavir Cancer Sansthan \& Research Centre, Patna, Bihar, India
}

\begin{abstract}
In recent times water pollution has become a gigantic health issue globally. Inorganic arsenic is one of water contaminant naturally present in very high concentration in the groundwater of many countries, creating an important public health issue affecting a population of 200 million globally. Arsenic exposure appears linked to increase in cancer, heart disease, and developmental problems. In Bihar 18 districts are affected with arsenic poisoning in groundwater. The maximum arsenic contamination in ground reported in Bihar till date is $1908 \mu \mathrm{g} \mathrm{L}^{-1}$ observed village Tilak Rai Ka Hatta (TRKH), Simri Block of Buxar District. The arsenic exposed population of study area has developed many visible symptoms of arsenic poisoning like hyperkeratosis of sole/palm along with melanosis and rain drop pigmentation. In the primary school, the highest arsenic concentration in drinking water observed was $857 \mu \mathrm{g} \mathrm{L}^{-1}$ while in the children hair sample the maximum value was $12.609 \mathrm{~m} \mathrm{~kg}^{-1}$. Finally, a community based arsenic filter based on adsorbent Hybrid Anion Exchange Nano Resin has been installed though joint initiative of Mahavir Cancer Sansthan \& Research Centre (MCSRC), Patna in collaboration with Lehigh University, Pennsylvania, USA, which changed the life of the population with symptomatic relief related to arsenic poisoning.
\end{abstract}

\section{INTRODUCTION}

The Gangetic flood plain region of Bihar is the most severely arsenic affected area with more than 5 million population. In Buxar district of Bihar, the Tilak Rai Ka Hatta (TRKH) village is the severely arsenic exposed area. The major chunk of population exhibits typical symptoms of arsenicosis. The highest arsenic concentration recorded in ground water was $1908 \mathrm{\mu g} \mathrm{L}^{-1}$. Many persons residing in this village had health related issues but the major intervention was made through installation of a community based arsenic filter, which changed the life of the population. There was significant decrease in the arsenic caused health issues in persons residing in study area.

\section{METHODS/EXPERIMENTAL}

\subsection{Location}

The study was done at Tilak Rai Ka Hatta village $\left(25^{\circ} 41^{\prime} 36^{\prime \prime} \mathrm{N}, 84^{\circ} 07^{\prime} 51^{\prime \prime} \mathrm{E}\right)$ of Buxar district of Bihar.

The population of the Tilak Rai Ka Hatta village is 5,348 with 340 households (Census, 2011).

\subsection{Sample collection \& survey}

A total of 65 hair samples of children aged between 4 years to 15 years from the primary school of the village with 03 sources of drinking water along with 80 water samples were randomly collected in duplicates from hand pumps of each household situated at every $50 \mathrm{~m}$. The depths of the handpumps were also recorded

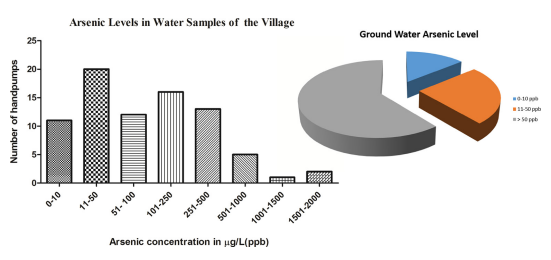

Figure 1. Arsenic concentration in water samples of Handpumps of Tilak Rai Ka Hatta analyses through GF-AAS with Pie chart (ANOVA-Dunnett's Test, $\mathrm{P}<0.05$ ).

for the correlation of arsenic concentration. After collection, all the hair samples were digested using concentrated $\mathrm{HNO}_{3}$ on hot plate under fume hood and total arsenic concentration (inorganic form) was estimated as per the protocol of (NIOSH, 1994) through graphite furnace atomic absorption spectrophotometer (Pinnacle 900T, Perkin Elmer, Singapore). Simultaneously, health assessment of the population was also done through a health survey questionnaire proforma. For determining the exact location of the hand pump, hand held Global Positioning System (GPS) receivers (Garmin etrex10, of USA) with an estimated accuracy of $\approx 10 \mathrm{~m}$ were utilized.

\section{RESULTS AND DISCUSSION}

\subsection{Arsenic assessment}

The study shows novel findings ever explored in this area. In the village TRKH the maximum arsenic concentration in water sample observed was $1908 \mu \mathrm{g} \mathrm{L}^{-1}$ (Fig. 1). 

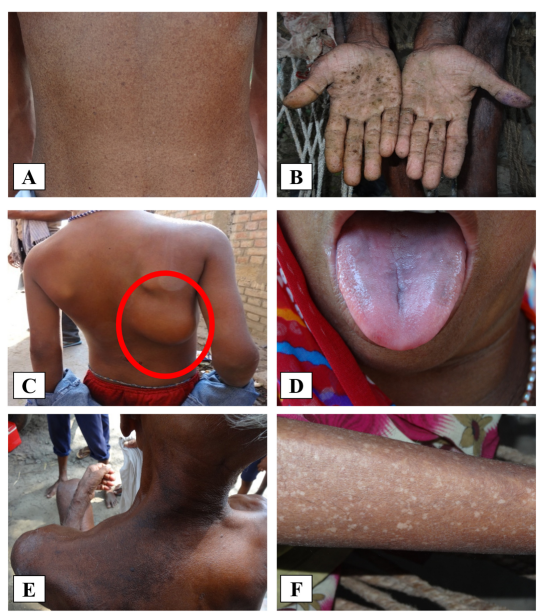

Figure 2. Showing arsenicosis symptoms in the population.
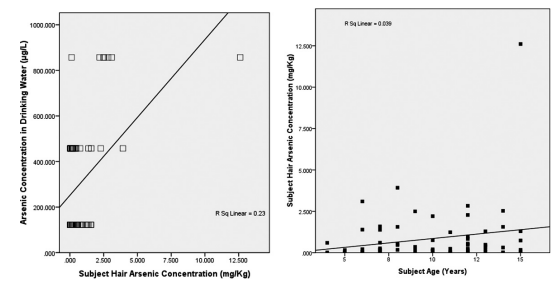

Figure 3. The correlation coefficient between arsenic concentration in drinking hand pump and arsenic concentration in the hair samples of the subjects $(r=0.23 \& \mathrm{P}<0.05)$ and arsenic concentration in drinking hand pump and subject age (years) $(\mathrm{r}=0.039 \& \mathrm{P}<0.05)$.

\subsection{Health assessment}

The rural population exhibited the typical symptoms of arsenicosis like hyperkeratosis in palm and sole, melanosis in palm and sole, blackening of tongue, skin irritation, anemia, gastritis, constipation, loss of appetite, bronchitis and cough, etc. (Fig. 2).

Correlation coefficient of arsenic concentration in handpump water and arsenic concentration in the hair samples of the subjects shows the maximum arsenic concentration in the hand pump of the school as $857 \mu \mathrm{g} \mathrm{L}^{-1}$ while the maximum arsenic concentration in the hair sample was $12.609 \mathrm{mg} \mathrm{kg}^{-1}$ correlates the arsenic exposure $(\mathrm{r}=0.23, \mathrm{P}<0.05$; Fig. 3$)$.

Arsenic determination in urine, hair and nail are considered as most reliable indicator of exposure. Hair samples are used as a biomarker for arsenic exposure because inorganic arsenic and Dimethylarsinic acid are stored in hair root and thus reflect past exposure (Yoshida et al., 2004). An elevated arsenic level in hair indicates the past exposure of 6-12 months (NRC, 2001). In the present study, very high concentration of arsenic contamination was observed in the hair samples of the children. They were drinking water from three highly arsenic contaminated handpumps. The most fascinating result was that many cancer cases were also reported from these villages i.e. skin cancer, gall bladder cancer and breast cancer cases.
The other health related assessments showed hormonal imbalance in the population. The rural population exhibited elevated levels of serum estrogen while decreased levels of serum testosterone levels denotes that the arsenic contamination in groundwater and its consumption by the rural population has caused severe health problems to them (Kumar et al., 2015, 2016). The entire study thus reveals that high arsenic concentration in groundwater in these two villages and drinking of this contaminated water has led to severe health related problems in the population.

\subsection{Mitigation}

A community based arsenic filter was installed in the study area with the help of community participation through collaborative effort of Mahavir Cancer Institute and Research Centre, Patna and Lehigh University, Pennsylvania, USA, which is based on adsorbent Hybrid Anion Exchange Nano Resin. This filter is providing arsenic safe water giving good health outcomes.

\section{CONCLUSIONS}

The survey of the village TRKH of Buxar district, demonstrated very high arsenic concentration in drinking water as well as in the hair samples of the school children. Many arsenic induced health related problems were observed in the population like keratosis, melanosis, leuco-melanosis, hormonal imbalance and few cases of cancer. The arsenic filter installed through community participation was successful and sustainable initiative. Installation of arsenic filter has changed the health status of the arsenic exposed village population.

\section{ACKNOWLEDGEMENTS}

The authors acknowledge Tagore-Sengupta Foundation for providing fund for installation of Arsenic filter.

\section{REFERENCES}

Census 2011. Interim Report of Population Census of India. http://www.censusindia.gov.in/2011.

Kumar, A., Ali, M., Rahman, S.M., Iqubal A.M., Anand, G. \& Niraj, P.K. 2015. Ground water arsenic poisoning in "Tilak Rai Ka Hatta" village of Buxar District, Bihar, India causing severe health hazards and hormonal imbalance. $J$. Environ. Anal. Toxicol. 5(4): 1-7.

Kumar, A., Kumar, R., Rahman, M.S., Iqubal, M., Ali, M., Niraj, P.K., Anand, G., Prabhat, K., Abhinav \& Ghosh, A. K. 2016. Ground water arsenic contamination: a local survey in India. Int. J. Prev. Med. 7: 100.

NRC 2001. Arsenic in drinking water. 2001 update. The National Academies Press, Washington, DC.

Yoshida, T., Yamauchi, H. \& Fan, S.G. 2004. Chronic health effects in people exposed to arsenic via the drinking water: dose-response relationships in review. Toxicol. Appl. Pharmacol. 198(3): 243-252. 